\title{
Potret Pembelajaran Pada Anak Tunagrahita Di Sekolah Luar Biasa Bhakti Pemuda Kota Kediri
}

\author{
Novie Putri Amalia, ${ }^{1}$ Makhfud $^{2}$ \\ ${ }^{1}$ Institut Agama Islam Tribakti Kediri, ${ }^{2}$ Institut Agama Islam Tribakti Kediri \\ ${ }^{1}$ putryamalia521@yahoo.co.id, ${ }^{2}$ makhfudgurah@gmail.com
}

\begin{abstract}
This article discusses how the learning of Islamic Religious Education for mentally retarded children in Extraordinary Schools (SLB). Extraordinary Schools (SLB) are special schools for school-age children who have "special needs". Children with intellectual disabilities have IQs below the average normal child in general, thus causing their intellectual and intellectual functions disrupted which causes other problems that arise during their development. Islamic education is not only given to normal children, but also to children who have disabilities or mental disorders. This study uses qualitative research and uses a phenomenological approach. Data collection methods are observation, interviews, and documentation. The results of this study state that the implementation of Islamic Religious Education learning for mentally retarded children in SLB Bhakti Pemuda City of Kediri emphasizes memorization and practice directly with concrete or tangible objects, and is evaluated in three domains, namely cognitive, affective, and psychomotor. However, the evaluation of learning in SLB Bhakti Pemuda Kota Kediri is more measured from the realm of affective (attitude and values) and psychomotor (skills or skills).
\end{abstract}

Keywords: Learning, Islamic Education, Mentally Impaired.

\begin{abstract}
Abstrak
Artikel ini membahas bagaimana pembelajaran Pendidikan Agama Islam anak tunagrahita di SLB. Sekolah Luar Biasa (SLB) merupakan sekolah khusus bagi anak usia sekolah yang memiliki "kebutuhan khusus". Anak tunagrahita memiliki IQ di bawah rata-rata anak normal pada umumnya, sehingga menyebabkan fungsi kecerdasan dan intelektual mereka terganggu yang menyebabkan permasalahan-permasalahan lainnya yang muncul pada masa perkembangannya. Pendidikan Agama Islam tidak hanya diberikan kepada anak normal saja, tetapi juga diberikan kepada anak yang mempunyai kelainan atau mental. Penelitian ini menggunakan penelitian kualitatif dan menggunakan pendekatan fenomenologi. Metode pengumpulan datanya adalah observasi, wawancara, dan dokumentasi. Hasil penelitian ini meyatakan bahwa Pelaksanaan pembelajaran Pendidikan Agama Islam bagi anak tunagrahita di SLB Bhakti Pemuda Kota Kediri adalah lebih menekankan pada hafalan dan praktik secara langsung dengan benda-benda yang konkrit atau nyata, dan dievaluasi dengan tiga ranah, yaitu kognitif, afektif, dan psikomotorik. Akan
\end{abstract}


tetapi evaluasi pembelajaran di SLB Bhakti Pemuda Kota Kediri lebih diukur dari ranah afektif (sikap dan nilai) dan psikomotoriknya (keterampilan atau skill).

Kata Kunci: Potret Pembelajaran, Pendidikan Agama Islam, Anak Tunagrahita

\section{Pendahuluan}

Setiap individu tidak dilahirkan dengan keadaan yang sama, terdapat beberapa anak yang dilahirkan dalam keadaan yang sempurna. Namun sebagai manusia, mereka memiliki hak yang sama seperti individu lain yang dilahirkan sempurna. Salah satu hak tersebut adalah mendapat pendidikan yang layak sebagaimana amanat Undang-Undang Dasar 1945 serta Undang-undang sikdisnas No. 20 tahun 2003, bahwa keterbatasan tidak menjadi pembatas untuk mendapatkan pendidikan.

Pendidikan agama Islam tidak hanya diberikan kepada anak normal saja, tetapi juga diberikan kepada anak yang mempunyai kelainan atau mental. Karena manusia mempunyai hak yang sama dihadapan Allah SWT. Anak tunagrahita pada hakikatnya sama seperti anak normal biasanya, mereka dianugerahi otak namun mempunyai keterbatasan dalam segi kecerdasan, ia juga memiliki potensi-potensi positif yang dapat berkembang. Oleh karena itu dibutuhkan bimbingan dan pendidikan bagi mereka, khususnya pendidikan agama Islam. ${ }^{1}$

Penting untuk mengembangkan model pendidikan Islam pada anak berkebutuhan khusus, khususnya anak tunagrahita. Nantinya mereka akan memiliki pengertian, pengetahuan, pemahaman, dan pengalaman pembelajaran Islam yang baik, meskipun keadaan mereka nantinya tidak seperti pelajar biasa lainnya. Ajaran dalam agama Islam pada siswa berkebutuhan khusus secara resmi perlu dikembangkan berdasarkan karakter dan kemampuan mereka.

Pada tahap selanjutnya semakin banyak pihak sepakat bahwa pendidikan $A B K$, diantaranya tunagrahita harus dipromosikan dan didukung,. Namun masih menyisakan pertanyaan yang belum terjawab tentang apa arti pendidikan bagi tunagrahita, dalam teori maupun praktiknya. Bagaimana layanan yang sesuai bagi anak tunagrahita, dari aspek kelembagaan maupun profil pendidiknya.

1 M. Maftuhin and A. Jauhar Fuad, "Pembelajaran Pendidikan Agama Islam Pada Anak Berkebutuhan Khusus," Journal An-Nafs: Kajian Penelitian Psikologi 3, no. 1 (June 24, 2018): 83-98-8398 
Anak tunagrahita adalah anak yang memiliki keterbatasan secara mental atau dapat dikatakan sebagai anak yang memiliki kelemahan dalam berpikir. Anak tunagrahita adalah individu yang secara signifikan memiliki intelegensi dibawah normal dengan skor IQ sama atau lebih rendah dari 70. Intelegensi yang yang dibawah rata-rata anak normal, jelas ini akan menghambat segala aktifitas kehidupannya. Sehari- hari, dalam bersosialisasi, komunikasi dan yang lebih menonjol adalah ketidak-mampuannya dalam menerima pelajaran yang bersifat akademik sebagaimana anak-anak sebayanya. ${ }^{2}$

Pada keilmuan psikologi perkembangan, istilah ABK diantaranya tunagrahita ditujukan kepada kelompok anak memiliki kelainan atau perbedaan dari segi fisik, mental, emosi dan sosial. Dalam keompok ini disebut juga gabungan ciri-ciri yang menyebabkan mereka terhambat dalam mencapai perkembangan secara maksimal. Dengan kondisi seperti ini, mereka membutuhkan layanan khusus. Tegasnya tunagrahita adalah anak yang memiliki kemampuan intelektual di bawah kemampuan anak sebayanya. $^{3}$

Islam secara prinsip juga memberikan isyarat bahwa dalam pendidikan tidak ada diskriminatif. Manusia memiliki hak dan posisi yang sama dalam semua bidang kehidupan termasuk pendidikan. Al-Qur'an dan Hadis banyak megemukakan dan mengisyaratkan tentang orang difabel atau orang cacat dan memiliki keterbatasan fisik.

Ada kisah menarik dalam Al-qur'an tentang orang cacat, yaitu tuna netra. Allah SWT mengingatkan Nabi Muhammad SAW agar berlaku adil, kasih sayang dan bijak dalam melayani orang cacat. Pada Q.S 'Abasa [80] 116, Allah SWT mengisyaratkan tentang pentingnya menjaga kepedulian terhadap nasib dan pendidikan orang-orang cacat. ${ }^{4}$ hal ini sejalan dengan definisi pendidikan Islam, yaitu usaha menyiapkan manusia seutuhnya baik akal dan hatinya, rohani dan jasmaninya, akhlak dan keterampilannya.

Sejalan dengan hal ini adalah tugas pendidikan Islam untuk memaksimalkan potensi dan kemanusiaan mereka, potensi fisik, keterampilan, kecerdasan, moral, dan sebagainya, sehingga mereka dapat menjalankan fungsi hidup mereka, sebagai hamba Allah dan khalifahnya. . Berkenaan dengan penjelasan itu, penting untuk mengembangkan model pada pendidikan Islam anak-anak dengan cacat intelektual, sehingga mereka akan memiliki pengetahuan, pemahaman, dan pengalaman dalam

\footnotetext{
${ }^{2}$ Kemis and Ati Rosnawati, Pendidikan Anak Berkebutuhan Khusus Tuna Grahita : Peserta Didik Berkebutuhan Khusus Dengan Hambatan Kecerdasan (Jakarta Timur: Luxima Metro Media, 2003), 1.

${ }^{3}$ Rini Handayani, Psikologi Perkembangan Anak (Jakarta: Universitas Terbuka, 2007), h. 79.

${ }^{4}$ Muchafid Anshori, Pendidikan Agama Islam Adaptif di Sekolah Luar Biasa (Jakarta: Pustikom,
} 2012), h. 51. 
pembelajaran Islam, meskipun tidak seperti siswa lainnya. Instruksi tentang agama Islam tentang siswa jenis ini secara formal perlu dikembangkan dengan memperhatikan karakter dan kemampuan mereka. Tujuan instruksional harus dipetakan tingkat intelegensi mereka, metode ini harus difokuskan pada pendekatan pemodelan individu sehubungan dengan psikologi dan agama. Harus ada kemampuan khusus milik guru yang mengajar di sekolah intelektual Intelektual yang berasal dari Departemen Pendidikan Islam seperti keterampilan komunikasi yang baik. ${ }^{5}$

Pembelajaran untuk tunagrahita, hendaknya lebih diarahkan pada membangun kejiwaannya yang labil, kepercayaan diri yang hilang, dan memberikan layanan psikoterapi untuk meluruskan tingkah laku yang disandangnya. Untuk itu pengintegrasian bimbingan konseling, terapi religius dalam proses pembelajaran menjadi bagian yang tepat untuk mengatasi kesulitan belajar dan problematikannya. ${ }^{6}$ Selain itu, system pembelajaran bagi anak tunagrahita harus dilaksanakan dengan sesederhana mungkin agar dapat dengan mudah dipahami oleh peserta didik. ${ }^{7}$

\section{Metode Penelitian}

Penelitian ini merupakan penelitian kualitatif, karena penelitian kualitatif jauh lebih subjektif dari pada penelitian kuantitatif. Artikel ini juga menggunakan pendekatan fenomenologi (phenomenal studies). Sumber data pada penelitian ini adalah hasil observasi penulis secara langsung dalam obyek penelitian. Dalam hal ini menggunakan satu sumber data yaitu sumber data primer. Dalam hal ini, data yang penulis maksudkan adalah segala hal yang berkaitan dengan obyek penelitian yang peneliti dapatkan langsung dari obyek penelitian, baik menggunakan wawancara mendalam, pengamatan, dokumentasi dan lain sebagainya. Prosedur pengumpulan data diperoleh dari hasil observasi, wawancara, dan dokumentasi.

Teknik analisis data menurut Patton adalah proses mengatur urutan data, mengorganisasikannya, dalam sutu pola, kategori dan satu uraian dasar. ${ }^{8}$ Analisa data berbeda dengan penafsiran, yaitu memberikan arti yang signifikan terhadap analisis,

\footnotetext{
${ }^{5}$ Aziza Meria, "Model Pembelajaran Agama Islam bagi Anak Tunagrahita di SDLBYPPLB Padang Sumatra Barat," TSAQAFAH 11, no. 2 (November 30, 2015): 355-80, https://doi.org/10.21111/tsaqafah.v11i2.273.

6 Abu Bakar, M. Luddin, Dasar-Dasar Konseling Tinjauan Teori dan Praktik (Bandung: Cipta Pustaka, 2010), h. .80.

${ }^{7}$ Fipta Oktorina, "Pendidikan Agama Islam Pada Anak Tunagrahita Di SDLB Negeri Bengkulu Tahun Pelajaran 2017-2018," At-Ta'lim : Media Informasi Pendidikan Islam 17, no. 1 (October 5, 2018): 81-94, https://doi.org/10.29300/attalim.v17i1.1182.

${ }^{8}$ Moh. Kasiram, Metodologi Penelitian Kualitatif-Kuantitatif (Malang: UIN Maliki Perss, 2008), h. 228 .
} 
menjelaskan pola uraian dan mencari hubungan antara dimensi-dimensi uraian. Setelah data itu terkumpul kemudian dijadikan konsklusi. Analisa data pada penelitian kualitatif berlangsung selama dan pasca pengumpulan data. Sebagaimana dinyatakan oleh Milles dan Haberman, analisa data kualitatif dikatakan sebagai model alir (Follow Model). ${ }^{9}$ Oleh kerena itu, proses analisa data mengalir dari tahap awal sampai tahap penarikan kesimpulan study. Adapun metode yang digunakan penulis dalam menganalisa data adalah: Reduksi data, penyajian data, Penarikan kesimpulan dan verifikasi.

\section{Hasil dan Pembahasan}

\section{Perencanaan Pembelajaran PAI bagi anak Tunagrahita}

Terry (1993) mengungkapkan bahwa perencaaan itu pada dasarnya adalah penetapan pekerjaan yang harus dilaksanakan oleh kelompok untuk mencapai tujuan yang telah ditentukan ${ }^{10}$. William H. Newman dalam bukunya Administrative Action Techniques of Organization and Management: mengemukakan bahwa "perencanaan adalah menentukan apa yang akan dilakukan .

Bahwa pada dasarnya segala sesuatu harus direncanakan terlebih dahulu sehingga proses pembelajaran berlangsung dengan lancar. Dalam konteks ini kreatifitas guru sangat dibutuhkan. Ide kreatifnya diperlukan dalam memfasilitasi yang kaitanya dengan membuat perencanaan pembelajaran baik dalam kaitanya dengan pembuatan silabus, dan rencana pelaksanaan pembelajaran. Perencanaan disusun guru dalam jangka waktu tertentu, hal ini disesuaikan dengan kurikulum, materi dan kebutuhan akan proses pembelajaran. Dalam perencanaan haruslah disesuaikan dengan materi yang akan dikaji, metode, tempat pembelajaran, strategi, bahkan media/alat peraga yang tersedia di sekolah yang dapat mendukung dalam proses pembelajaran di dalam kelas.

\section{Pelaksanaan Pembelajaran PAI bagi anak Tunagrahita}

Proses pembelajaran dalam Pendidikan Agama Islam selalu memperhatikan individu peserta didik, membantu siswa dalam memaksimalkan kemampuan yang dimilikinya, serta kemampuan untuk berinteraksi secara fisik dan sosial terhadap lingkungan, sehingga bagi peserta didik, belajar merupakan hal yang menyenangkan dan sekaligus mendorong kepribadianya berkembang secara optimal. Sedangkan bagi guru

\footnotetext{
${ }^{9}$ Agus Salim, Teori dan Paradigma Penelitian Sosial (Yogyakarta: Tiara Wacana, 2006), h.23.

${ }^{10}$ Wina Sanjaya, Perencanaan dan Desain Sistem Pembelajaran, (Jakarta: Kencana, Maret 2011), cet II, hal. 24
} 
proses pembelajaran merupakan suatu kewajiban yang bernilai ibadah yang harus dipertanggung jawabkan.

Adapun langkah-langkah pembelajaran Pendidikan Agama Islam bagi anak tunagrahita adalah sebagai berikut :

a. Strategi dalam pembelajaran anak Tunagrahita

Strategi bisa diartikan sebagai pola-pola umum kegiatan guru dan anak didik dalam perwujudan kegiatan belajar mengajar untuk mencapai suatu tujuan yang telah di gariskan. ${ }^{11}$ Strategi pembelajaran memegang peran penting dalam menunjang proses pembelajaran. Penerapan strategi biasanya beriringan dengan penerapan metode dalam pembelajaran digunakan oleh seorang pengajar untuk menyampaikan materi pembelajaran, sehingga akan memudahkan peserta didik menerima dan memahami materi pembelajaran yang disampaikan oleh guru.

Pelaksanaan strategi pembelajaran bagi anak tunagrahita menekankan pada keterkaitan antara materi pembelajaran dengan dunia kehidupan peserta didik secara nyata, dengan menunjukkan hal-hal yang langsung bisa dilihat sesuai dengan materi yang diajarkan, karena anak tunagrahita sangat sulit untuk memahami hal-hal yang bersifat teoritis. Misalnya manakala kita ingin menunjukkan ciptaan Tuhan kita memberikan contoh visual/bisa dilihat langsung, memberikan contoh nilai-nilai kebaikan misalnya membantu teman yang membutuhkan, saling menghargai satu sama lain, tidak mengambil barang teman secara diam-diam, dan saling tolong menolong. Selain itu para siswa juga diajar secara individual. Artinya, guru mengajar siswa secara perseorangan sesuai dengan kemampuanya dalam mengikuti proses pembelajaran.

b. Metode pembelajaran anak Tunagrahita

Metode pembelajaran adalah suatu cara/ upaya yang dilakukan oleh para pendidik agar proses belajar mengajar para siswa tercapai sesuai dengan tujuan. Metode juga merupakan salah satu komponen yang tidak kalah perananya dari komponen lainya dalam pembelajaran agama Islam. Metode pembelajaran dalam pelaksanaan pembelajaran agama Islam sangat menunjang keberhasilan tujuan dalam pembelajaran.

c. Materi Pembelajaran anak Tunagrahita hlm. 5 .

${ }^{11}$ Syaiful Bahri Djamarah dan Aswan Zain, Strategi Belajar Mengajar (Jakarta: Rineka Cipta,2006), 
Materi pembelajaran Pendidikan Agama Islam disesuaikan dengan kemampuan dan kondisi anak tunagrahita dan tidak bisa disamakan dengan materi yang diajarkan pada anak normal. Materi-materi yang disampaikan kepada anak tunagrahita juga disusun sesederhana mungkin untuk memudahkan dalam menangkap dan memahami materi yang disampaikan oleh guru. Dalam proses pembelajaran Pendidikan Agama Islam, guru lebih menekankan pada akhlak dan fiqih, karena diharapkan siswa nantinya dapat berakhlak dan bertingkah laku yang baik kepada orang tua, guru, dan teman baik di lingkungan keluarga, sekolah, dan masyarakat, serta dapat melaksanakan sholat dalam kehidupan sehari-hari. Hal ini disebabkan oleh intelektual di bawah rata-rata, sehingga anak tunagrahita membutuhkan materi yang bersifat kongkrit dan praktis.

d. Media Pembelajaran anak Tunagrahita

Media merupakan suatu komponen penting dalam proses belajar mengajar, yaitu sebagai perantara, pengantar, atau sarana yang dapat digunakan untuk menyampaikan informasi dan memberikan pengalaman kepada siswa, mendorong motivasi belajar siswa, memperjelas dan mempermudah konsep yang abstrak serta mempertinggi daya serap. Dalam proses pembelajaran media merupakan salah satu penunjang dalam proses pembelajaran. Penggunaan media pembelajaran pada anak tunagrahita lebih sering menggunakan benda konkrit yang langsung bisa dipraktikkan oleh siswa, seperti tatacara berwudhlu, shalat di mushola, dengan bimbingan guru PAI sehingga sangat mudah untuk dipahami. Karena anak tunagrahita kurang memahami hal-hal yang bersifat abstrak dalam menangkap pelajaran.

e. Kendala selama proses pembelajaran berlangsung

Kendala yang dihadapi guru PAI dalam proses pembelajaran bagi anak tunagrahita yaitu, pertama kemampuan siswa yang berbeda, sehingga sulit bagi guru dalam menjelaskan dan menyampaikan materi, karena setiap anak harus dilayani dengan cara yang berbeda-beda. Jadi guru PAI lebih mengutamakan kesabaran dalam membimbing, kedua karakter anak yang tidak sama, anak tunagrahita tidak bisa berbicara dengan lancar dan harus dibimbing terus.

\section{Evaluasi Pembelajaran PAI bagi anak Tunagrahita}

Evaluasi pembelajaran dapat diartikan sekumpulan komponen yang saling berkaitan satu sama lain yang saling berkolaborasi didalam membuat program perencanaan, pelaksanaan dan pelaporan hasil evaluasi yang dilaksanakan di Sekolah Penyelenggara Pendidikan Inklusif untuk membantu guru dalam menempatkan peserta 
didik dalam kelompok tertentu sesuai dengan kemampuan dan kecakapan masing-masing serta membantu guru dalam menyusun rencana evaluasi, menentukan waktu pelaksanaan dan melaporkan hasilnya yang tidak membuat kesenjangan antara kenyataan dan harapan.

Berdasarkan Peraturan pemerintah Republik Indonesia nomor 19 tahun 2005 tentang Standar Nasional Pendidikan, penilaian pendidikan terdiri atas: penilaian hasil belajar oleh pendidik, penilaian belajar oleh satuan pendidikan, dan penilaian hasil belajar oleh pemerintah. Penilaian terdiri atas penilaian eksternal dan penilaian internal. Penilaian eksternal merupakan penilaian yang dilakukan oleh pihak lain yang tidak melaksanakan proses pembelajaran. Penilaian eksternal dilakukan oleh suatu lembaga, baik dalam maupun luar negeri yang dimaksudkan untuk penegnadalian mutu. Adapun penilaian internal adalah penilaian yang dilakukan dan direncanakan oleh guru pada saat pembelajaran berlangsung dalam rangka penjaminan mutu.

Evaluasi merupakan salah satu komponen penting dan tahap yang harus ditempuh oleh seorang guru untuk mengetahui keefektifan dalam pembelajaran. Arifin mengemukakan bahwa pada hakikatnya evaluasi adalah suatu proses yang sistematis dan berkelanjutan untuk menentukan kualitas (nilai dan arti) dari pada sesuatu, berdasarkan pertimbangan dan kriteria tertentu dalam rangka mengambil suatu keputusan. ${ }^{12}$ Hasil yang diperoleh dapat dijadikan umpan balik (feed back) bagi guru PAI dalam memperbaiki dan menyempurnakan kegiatan pembelajaran. Dalam mengevaluasi anak tunagrahita tidak semudah mengevaluasi anak normal, karena walaupun sama-sama satu kelas tetapi karakteristik siswa berbeda-beda. Untuk mengevaluasi anak tunagrahita tidak hanya mengevaluasi masalah pengetahuan/kognitif nya saja, karena dari segi pengetahuan banyak siswa yang kurang paham/mengerti. Jadi harus banyak menggali pengetahuanya dengan hasil pengamatan dan praktik langsung. Namun demikian pelaksanaan evaluasi pada pembelajaran anak tunagrahita harus disesuaikan dengan kemampuan siswa berkebutuhan khusus. Selain berada dalam ruangan khusu, siswa ABK juga didampingi pengawas dan guru pendamping. ${ }^{13}$

\section{Kesimpulan}

1. Perencanaan pembelajaran Pendidikan Agama Islam bagi anak tunagrahita di SLB Bhakti Pemuda Kota Kediri adalah dengan menganalisis hari efektif, menyusun hlm. 4.

12 Asrul, Rusydi Ananda, dkk, Evaluasi Pembelajara n (Bandung: PT. Citrapustaka Media, 2014),

${ }^{13}$ Lilik Maftuhatin, "Evaluasi Pembelajaran Anak Berkebutuhan Khusus (Abk) Di Kelas Inklusif Di SD Plus Darul 'Ulum Jombang,” Religi: Jurnal Studi Islam 5, no. 2 (October 10, 2014): 201-27. 
silabus, menyusun Rencana Program Pembelajaran (RPP), dan melakukan evaluasi atau penilaian.

2. Pelaksanaan pembelajaran Pendidikan Agama Islam bagi anak tunagrahita di SLB Bhakti Pemuda Kota Kediri adalah lebih menekankan pada hafalan dan praktik secara langsung dengan benda-benda yang konkrit atau nyata, karena anak tunagrahita memiliki keterbatasan dalam menangkap suatu pembelajaran yang bersifat teoritis selayaknya anak normal. Adapun tujuana yaitu agar dapat mengaplikasikan ajaran Agama Islam dalam kehidupan sehari-hari.

3. Evaluasi pembelajaran Pendidikan Agama Islam bagi anak tunagrahita di SLB Bhakti Pemuda Kota Kediri adalah dilakukan dengan tiga ranah, yaitu kognitif, afektif, dan psikomotorik. Akan tetapi evaluasi pembelajaran di SLB Bhakti Pemuda Kota Kediri lebih diukur dari ranah afektif (sikap dan nilai) dan psikomotoriknya (keterampilan atau skill).

\section{Daftar Pustaka}

Anshori, Muchafid. Pendidikan Agama Islam Adaptif di Sekolah Luar Biasa. Jakarta: Pustikom, 2012.

Asrul, dkk. Evaluasi Pembelajaran. Bandung: PT. Citrapustaka Media, 2014.

Bakar, Abu, M. Luddin. Dasar-Dasar Konseling Tinjauan Teori dan Praktik. Bandung: Cipta Pustaka, 2010.

Djamarah, Syaiful Bahri, dan Aswan Zain. Strategi Belajar Mengajar. Jakarta: Rineka Cipta, 2006.

Handayani, Rini. Psikologi Perkembangan Anak. Jakarta: Universitas Terbuka, 2007.

Maftuhin, M. and A. Jauhar Fuad, "Pembelajaran Pendidikan Agama Islam Pada Anak Berkebutuhan Khusus," Journal An-Nafs: Kajian Penelitian Psikologi 3, no. 1 (June 24, 2018): 83-98-83-98

Kasiram, Moh. Metodologi Penelitian Kualitatif-Kuantitatif. Malang: UIN Maliki Perss, 2008.

Kemis, and Ati Rosnawati. Pendidikan Anak Berkebutuhan Khusus Tuna Grahita: Peserta Didik Berkebutuhan Khusus Dengan Hambatan Kecerdasan. Jakarta Timur: Luxima Metro Media, 2003.

Maftuhatin, Lilik. "Evaluasi Pembelajaran Anak Berkebutuhan Khusus (Abk) Di Kelas Inklusif Di SD Plus Darul 'Ulum Jombang.’ Religi: Jurnal Studi Islam 5, no. 2 (October 10, 2014): 201-27. 
Meria, Aziza. "Model Pembelajaran Agama Islam bagi Anak Tunagrahita di SDLBYPPLB Padang Sumatra Barat." TSAQAFAH 11, no. 2 (November 30, 2015): 355-80. https://doi.org/10.21111/tsaqafah.v11i2.273.

Oktorina, Fipta. "Pendidikan Agama Islam Pada Anak Tunagrahita Di SDLB Negeri Bengkulu Tahun Pelajaran 2017-2018." At-Ta'lim : Media Informasi Pendidikan Islam 17, no. 1 (October 5, 2018): 81-94. https://doi.org/10.29300/attalim.v17i1.1182.

Salim, Agus. Teori dan Paradigma Penelitian Sosial. Yogyakarta: Tiara Wacana, 2006.

Sanjaya, Wina. Perencanaan dan Desain Sistem Pembelajaran. Jakarta: Kencana, Maret 2011. 